\title{
SERS of Dithiocarbamate Pesticides Adsorbed on Silver Surface; Thiram
}

\author{
Jae Soo Kang, Seon Yeong Hwang, Chul Jae Lee, and Mu Sang Lee ${ }^{\star}$ \\ Department of (hemisty Fincation, Kyunglook National Lhiversity, Daegu 702-701, Korea \\ Received.August 12,2002
}

\begin{abstract}
In the present work, we studied thiram on silver surface by SERS. Investigations of disulfides with SERS revealed that the molecules undergo a surface reaction on silver, namely easy cleavage of the $\$-S$ bond. We believe that the two S atoms of resonance fomed from the thiram may be chemisotbed strongly on $\Lambda \mathrm{g}$ sol. This resonance form adheres perpendicularly to the $\Lambda \mathrm{g}$ suface via the two $S$ atoms, since the $\delta\left(C_{3} H_{3}\right)$ and $v\left(C^{\prime} N\right)$ mode perpendicular to the surface showed strong enhancement. The important roles of halide anion adsorption have been discussed and the pI I effects of thiram on $\Lambda \mathrm{g}$ sol in acidic, neutral, and alkaline conditions were examined.
\end{abstract}

Key Words : Surlace-tnhanced Raman scattering, Thiram, Silver sol

\section{Introduction}

Many molecules adsorbed on appropriately prepared metal surfaces exhibit a Raman scattering cross section which is several orders of magnitude greater than the corresponding quantity for the isolated molecules. This effect, surface enhanced Raman scattering (SERS). ${ }^{1.2}$ provides a sensitive method for observing vibrational excitations of molecules that interact with metal surfaces. After the pioneering efforts by Fleiscluman. Van Duyne. Creighton and their co-workers. SERS spectroscopy has been extensively employed and is now established as a powerful and widely used method for studying vibrational spectra of a monolayer or submonolayer of adsorbed molecules on metal surfaces. ${ }^{3 .-1}$

Since the initial discovery of SERS from pyridine adsorbed on a silver electrode, a number of investigations for pyridine-silver systems have been reported and information about the mechanism of SERS has been obtained. SER spectra are obtained on a limited number of metal substrates such as Ag. Au. Cu. Pt. and alkali metals. ${ }^{j}$ Metal substrates generate intense SERS spectra comparable to those from the electrode systems and uniquely advantageous for theoretical analysis. The most often used as an active surface are silver sols. which possess several distinct advantages over silver electrodes. SERS spectroscopy has been successfully used to investigate the geometry, conformation. and chemical reaction of molecules adsorbed on metal surfaces. ${ }^{8-11}$ Even though the origins of the SERS phenomenon have still to be clearly defined. SERS nonetheless provides a powerful means for studying the in situ adsorption of a range of molecules onto an ever-increasing number of metal substrates.

The modern history of crop protection is little more than one hundred years old. but over this period enomous advances and some notable mistakes have been made." Unfortunately: fungicide has been used intensively. Additionally, pest and disease resistance affecting our crop protection capability and environmental pollutions produced by some agrochemicals are important growing concerns. ${ }^{1.3}$
So far, there have been many studies of variety agricultural fields. Additionally: many researchers have investigated spectroscopy with limited regard to agricultural medicines. Thus, we will observe SER spectra of thiram(tetrametlyylthiuramdisulfide)bis(dimethyl-thiocarbamyl)disulfideas an agricultural fungicide. Thiram is used to deal with weeds. apple anthrax. poly merization initiators. vulcanization accelerators, and verticillium of alfalfa.

The effects of solution $\mathrm{pH}$. anions. and solvents on the SERS behavior of adsorbates have been irrestigated by numerous researchers. ${ }^{14}$ Therefore, the overall aim of this paper is to outline the character and orientation of the thiram adsorbed on silver sol. The orientation of adsorbate-metal interaction is the principal focus of the present paper.

\section{Experimental Section}

Analytical-reagent grade thiram was purchased from Aldrich Co. and used without further purification. All procedures were accomplished with sonication. The solutions were prepared with triply distilled water and acetonitrile as an organic solvent.

The aqueous silver sol used in these experiments was prepared by reduction of $\mathrm{AgNO}_{3}$ with excess $\mathrm{NaBH}_{4}$ at room temperature as described in Creighton et al.s method. ${ }^{1.5}$ Briefly. a $1.0 \times 10^{-4} \mathrm{M}$ aqueous solution of thiram was mixed with the silver sol in a volume ratio of $1: 10$. A 0.1 $\mathrm{mL}$ volume of $0.5 \mathrm{M} \mathrm{KCl}$ solution was added to silver sol to prolong the silver colloid activity: Immediately after addition of thiram into the sol. the silver sol changed its color from greenish yellow to blue-gray due to aggregation. This bluegray colloid showed intense Raman scattering by adsorbed thiram in excitation at $514.5 \mathrm{~mm}$. The UV-VIS spectra prepared is displayed in Figure $I$ and shows a maximum at $398 \mathrm{~mm}$, with a shoulder peak at about $450 \mathrm{~mm}$. This result explains the characteristic of aggregated silver particles. in agreement with previous studies of many researchers.

The Raman instrument was equipped with a SPEX 1403 scamning double monochromator an RCA C31034 PMT 


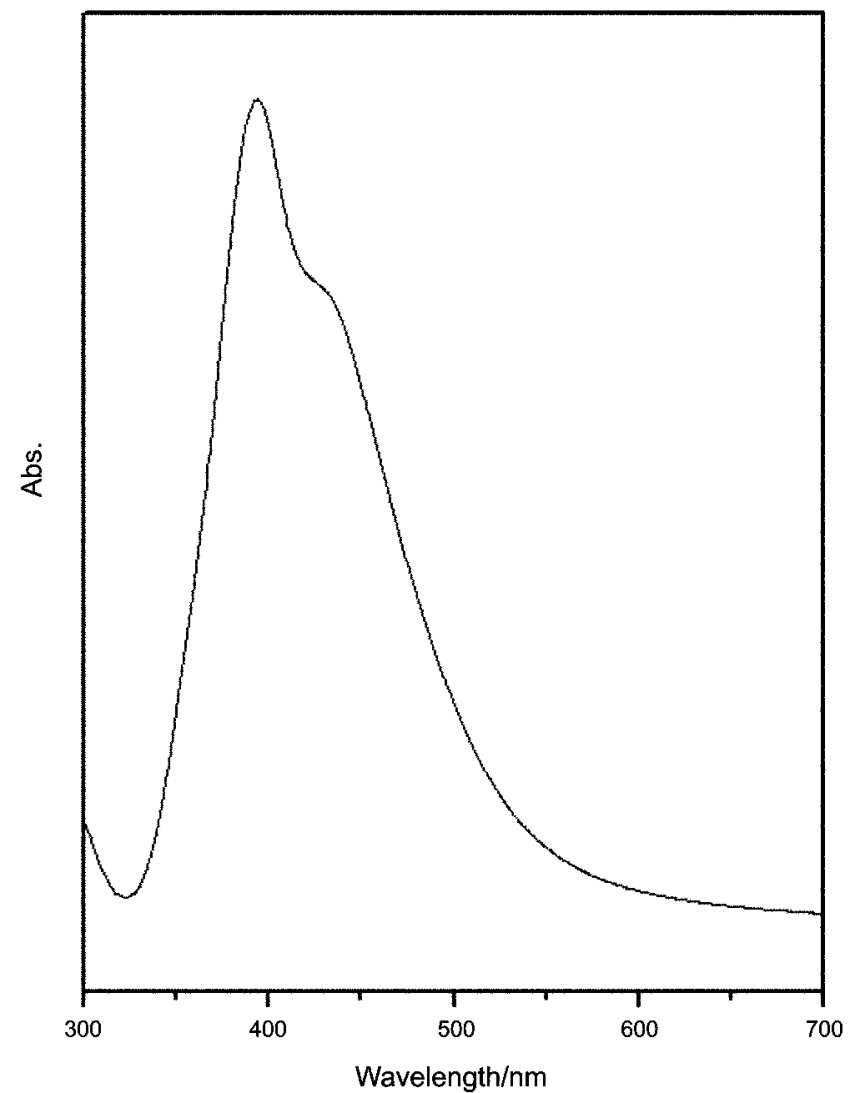

Figure 1. UV-Vis spectrum of silver sol.

detector, and SPEX DM 3000R software. Coherent lnnova $90-5$ argon ion laser $(51+.5 \mathrm{~nm})$ excitation was used. The laser power and the spectral slit widths used were $100-150$ $\mathrm{mW}$ and 600-800 $\mu \mathrm{m}$. respectively. The Raman in situ measurements were performed in the comentional way for samples with the observation direction perpendicular to the exciting light. UV-visible absorption spectra were measured using a Shimadzu UV-360 pc instmument. Infrared spectra were measured in $\mathrm{KBr}$ pellets with the aid of a Galaxy series FT-IR 7000 .

The $\mathrm{pH}$ of the solutions was adjusted by injecting the necessary amounts of $\mathrm{H}_{2} \mathrm{SO}_{4}$ and $\mathrm{NaOH}$ solutions of reagent grade and was checked before each day "s experiments. We examined SER spectra of thim containing $\mathrm{F}^{-} . \mathrm{Cl}^{-}, \mathrm{Br}^{-}$. and $\mathrm{l}^{-}$ions.

\section{Results and Discussion}

The Orientation of Adsorbates to the Metal. First of all. it is necessary to determine the molecular configuration and the resonance structures of thiram. According to the various IR. Raman spectra of the thiocarbonyl compounds which are linked to one or two nitrogen atoms. strong vibrational coupling effects are possible and the $\mathrm{C}=\mathrm{S}$ vibration is not localized. The IR and Raman spectra of thiram are shown in Figure 2.

Thiram consists of two planar $\mathrm{C}_{2} \mathrm{NCS}$ : units with a dihedral $\mathrm{C}-\mathrm{S}-\mathrm{S}-\mathrm{C}$ angle of $88.3^{\circ}$. The most important bond

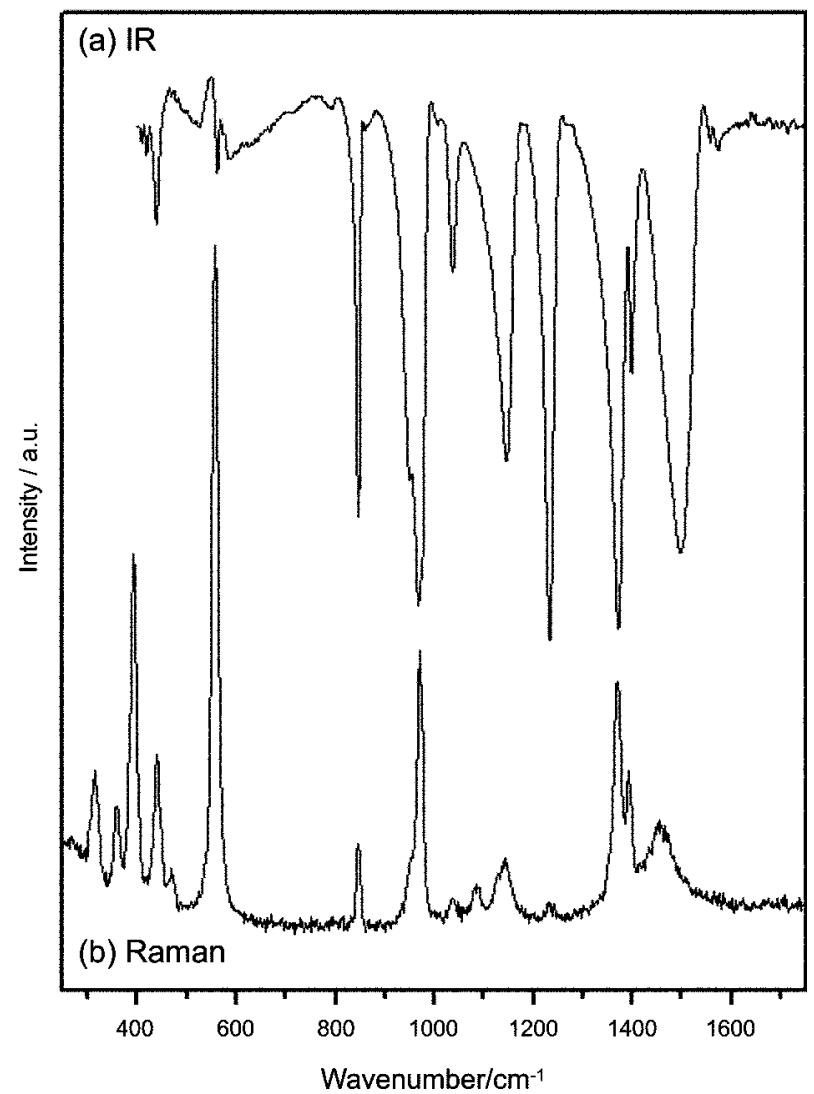

Figure 2. (a) IR and (b) Raman spectra of thiram (pure).

distances are $\mathrm{CH}_{3}-\mathrm{N}: 1.483$ and $1.506 \mathrm{~A}, \mathrm{C}-\mathrm{N}: 1.319 \mathrm{~A}$. $\mathrm{C}=\mathrm{S}: 1.63+\mathrm{A}$. C-S: $1.829 \mathrm{~A}$. and S-S: $2.005 \mathrm{~A}$. Therefore, thiram can be considered as two planar dimethyl-dithiocarbamate units joined by an $\mathrm{S}-\mathrm{S}$ bond: i.e.. the $\mathrm{C}_{2}-$ symmetry is retained. Thiram exhibits $C_{2}$-symmetry so that all IR modes are also Raman active, as shown in Figure 2.

For the disulfides, a report of SERS revealed that molecules with cleavage of the S-S bond undergo a surface reaction on silver ${ }^{1617}$ Additionally, we can easily understand the above bond distances. With the studies of reactions of sulfur compounds on various metals. imvestigations have shown that sulfur compounds are chemisorbed dissociatively on the metal surface by cleavage of $\mathrm{S}-\mathrm{S}$ bonds. These conclusions are reasonable given the adsorption of thiram on silver surface. Thus, it is explained in terms of resonance stnictures. as described in Figure 3. These compounds are stabilized by electron delocalization.

If bonding to the metal substrate is through the $\mathrm{S}$ atom. contributions from the resonance form will be increased. In this case. it is expected that the $\mathrm{S}-\mathrm{S}$ bonding is divided. the $v$ $(\mathrm{C}=\mathrm{S})$ and $v(\mathrm{C}-\mathrm{S})$ mode is decreased, and the $v(\mathrm{C}-\mathrm{N})$ mode is enhanced. However if the bonding is through the $\mathrm{N}$ atom. opposite results are expected.

In this paper, the IR. Raman. and SER spectra of thiram were measured in the solid and solution state in the region below $1800 \mathrm{~cm}^{-1}$. The IR spectrum of thiram in the range $4000-250 \mathrm{~cm}^{-1}$ has been reported for use as a reference spectrum in pesticide research. ${ }^{18}$ The ordinary Raman and 


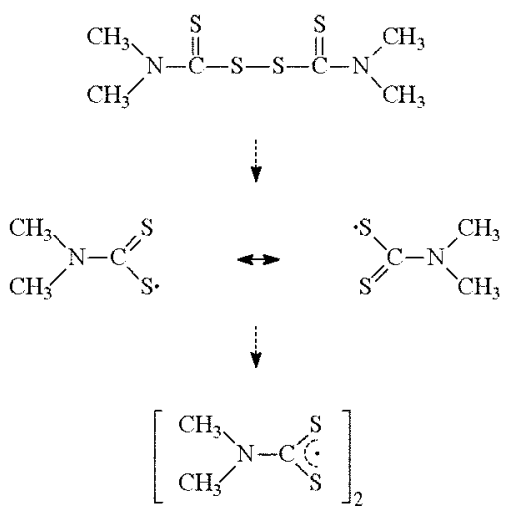

Figure 3. Structure and resonance structure of thiram.

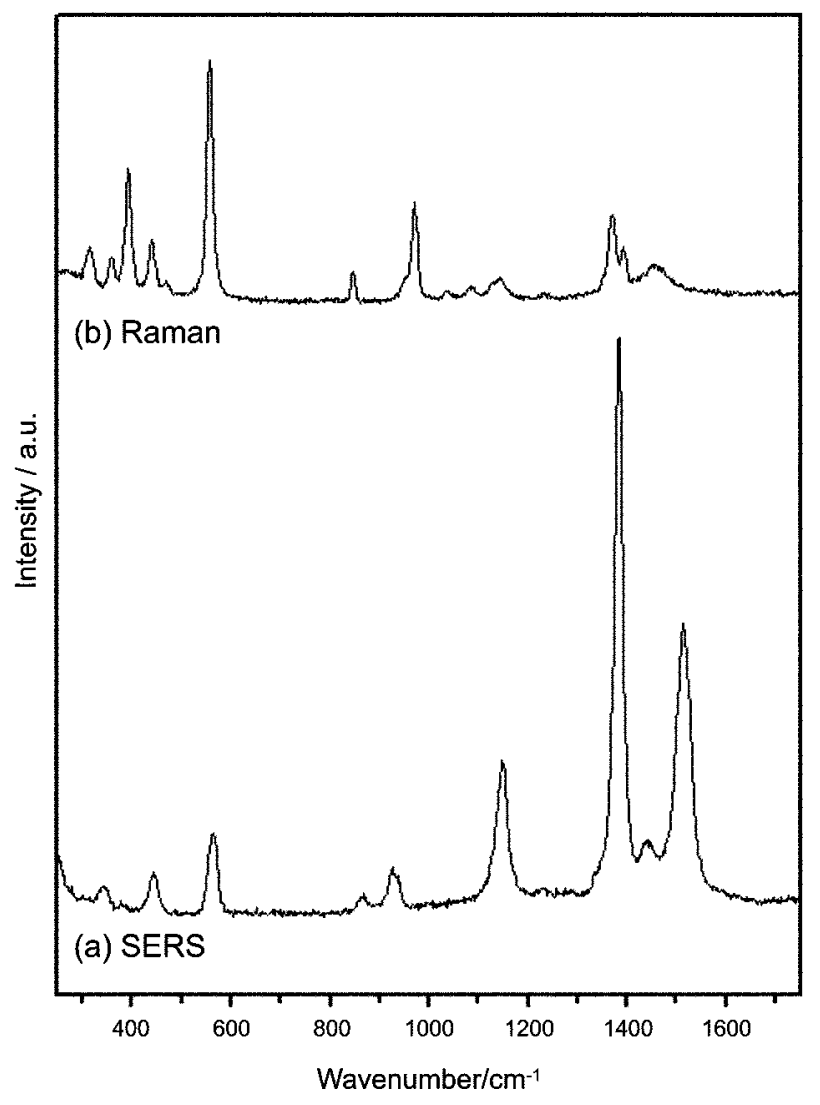

Figure 4. (a) SLRS $\left(1.0 \times 10^{+} \mathrm{M}\right)$ and (b) Raman(pure) specira of thirasts.

SER spectra of thiram are shown in Figure + and the major bands of the spectra are listed in Table 1 . The vibrational assignments shown in Table 1 for thiram have been made on the basis of assignments reported in the literature for the Raman and IR spectra of thiram, and by comparison with the thiram structure of similar thioureas and thioamides. ${ }^{19}$ ?i

By comparison of the above results. the orientation of metal-thiram interaction can be described approximately: The most prominent peak of the Raman spectnum is the $\mathbf{5 5 8}$ $\mathrm{cm}^{-1}$ mode in the ordinary Raman spectrum. The strong intensity band at $558 \mathrm{~cm}^{-1}$ is attributed mainly to the $v(\mathrm{~S}-\mathrm{S})$ mode of thiram. It is the band having the lowest depolarization ratio (0.14). The counterpart in the IR spectrum (Fig.
Table 1. Details of assignment of thiram

\begin{tabular}{|c|c|c|c|}
\hline IR & Raman & SH:RS & Assigmment \\
\hline & & $226(\mathrm{vw})$ & $v(\mathrm{Ag}-\mathrm{S})$ \\
\hline & & $236(17 w)$ & $v(\mathrm{Ag}-\mathrm{CI})$ \\
\hline & $316(\mathrm{~ms})$ & $342(\mathrm{~m}, \mathrm{br})$ & $\delta(\mathrm{S}-\mathrm{CS}), \delta(\mathrm{CSS})$ \\
\hline & $360(\mathrm{~m})$ & & $v\left(\mathrm{CI} \mathrm{I}_{3} \mathrm{NC}\right), v(\mathrm{CS})$ \\
\hline & $394(\mathrm{vs})$ & & $v_{s}(\mathrm{CSS}), \delta(\mathrm{CH})_{2} \mathrm{~N}, v(\mathrm{C}-\mathrm{S})$ \\
\hline $441(n)$ & $440(\mathrm{~ms})$ & $446(\mathrm{~m})$ & $\delta\left(\mathrm{C} \mathrm{H}_{3} \mathrm{NC}\right), v(\mathrm{C}-\mathrm{S})$ \\
\hline $563(\mathrm{vw})$ & $558(\mathrm{vs})$ & $564(\mathrm{mls})$ & $v(\mathrm{SS})$ \\
\hline $847(s)$ & $848(\mathrm{~m})$ & $870(\mathrm{vm})$ & $v\left(\mathrm{Cll}_{3} \mathrm{~N}\right)$ \\
\hline $951($ sh $)$ & 955 (wsh) & $928(\mathrm{~m})$ & $v\left(\mathrm{CH}_{3} \mathrm{~N}\right) \cdot v(\mathrm{C}-\mathrm{S})$ \\
\hline $969(\mathrm{~s})$ & $972(\mathrm{~s})$ & & $v_{i s}(\operatorname{CSS})$ \\
\hline \multirow[t]{2}{*}{$1038(w)$} & $1038(n \cdot b r)$ & & $\rho\left(\mathrm{CH}_{3}\right) \cdot v\left(\mathrm{CH}_{3} \mathrm{~N}\right)$ \\
\hline & $1088(\mathrm{w} \cdot \mathrm{br})$ & & $\rho\left(\mathrm{C}_{3}\right)$ \\
\hline $1147(\mathrm{~m})$ & $1144(n: b r)$ & $1150(\mathrm{~ms})$ & $\rho\left(\mathrm{CH}_{3}\right) \cdot v(\mathrm{CN})$ \\
\hline $1235(\mathrm{~s})$ & & & $v\left(\mathrm{CH}_{3} \mathrm{~N}\right) . \delta\left(\mathrm{CH}_{3} \mathrm{NC}\right)$ \\
\hline $1.373(\mathrm{~s})$ & $1372(s)$ & $1.386(\mathrm{vs})$ & $\delta_{s}\left(\mathrm{CH}_{3}\right), v(\mathrm{CN})$ \\
\hline \multirow[t]{2}{*}{$1400(\mathrm{~m})$} & $1396(s)$ & & $\delta_{s}\left(\mathrm{CH} \mathrm{I}_{3}\right)$ \\
\hline & $1456(\mathrm{~m}, \mathrm{br})$ & $1444(\mathrm{~m}, \mathrm{br})$ & $\delta_{3 \leqslant}\left(\mathrm{CII}_{3}\right)$ \\
\hline $1498(s, b r)$ & & $1514(\mathrm{mts})$ & $v(\mathrm{CN}), \delta\left(\mathrm{CH}_{3}\right), \rho\left(\mathrm{Cll}_{3}\right)$ \\
\hline
\end{tabular}

t) is only of weak strength. indicating that the change of dipole moment during the vibration is small. Then we will see that this band undergoes dramatic changes in both the relative intensity and frequency in the SER spectra. Additionally, two bands at $316.394 \mathrm{~cm}^{-1}$ decrease in intensity: Thus, it is expected that the divided $S$ atom of thiram chemisorbs strongly on Ag surfaces.

It should be noted that the SER spectra of thiram between 1350 and $1550 \mathrm{~cm}^{-1}$ regions are not found in the ordinary Raman spectrum. Three distinct peaks at 1386.144 . and $1514 \mathrm{~cm}^{-1}$ were observed in the SER spectrum of thiram on the Ag surface. The strong bands of intensity appearing at 1386. $1+4+\mathrm{cm}^{-1}$ in the SER spectrum may be assigned to $\delta\left(\mathrm{CH}_{3}\right) . \quad \delta_{\mathrm{a}}\left(\mathrm{CH}_{3}\right)$. respectively; as shown in Table 1 . Especially; the band at $1386 \mathrm{~cm}^{-1}$ which is assigned to the $\delta\left(\mathrm{CH}_{3}\right)$ weakly coupled to the $v(\mathrm{CN})$. increased strongly. Moreover. the most dramatic difference was exhibited by the $1514 \mathrm{~cm}^{-1}$ line which didnt appear in the ordinary Raman spectrum. This new band is assigned to the $v(\mathrm{CN})$ mode by the IR and Raman spectra of thiram. The appearance of a $1514 \mathrm{~cm}^{-1}$ line reflects enhancement of the $v(\mathrm{CN})$ mode which is perpendicular to the Ag surface. Evidently. this mode has a low polarizability that is greatly enhanced after adsorption.

It can be assumed from the above results that the thiram molecule of resonance form having the cleavage of $S-S$ is bonded to perpendicularly to the metal.

It is suggested that the Raman lines near 316 and $394 \mathrm{~cm}^{-1}$ in Figure + are due to the $\delta$ ( $\mathrm{S}=\mathrm{C}-\mathrm{S})$. $v_{s}$ (CSS) mode decrease in the SERS. Joo et al. concluded that the C-S bonds did not cleave easily on SERS imvestigation of aliphatic sulfides adsorbed on silver. ${ }^{19.30}$ Therefore, the reduction of the intensity and the largest frequency shift at these peaks indicate that the two $\mathrm{S}$ atoms of thiram are bonded to the $\mathrm{Ag}$ surfaces. Thus, it can be concluded that the $v(\mathrm{C}-\mathrm{S})$ and $v$ 


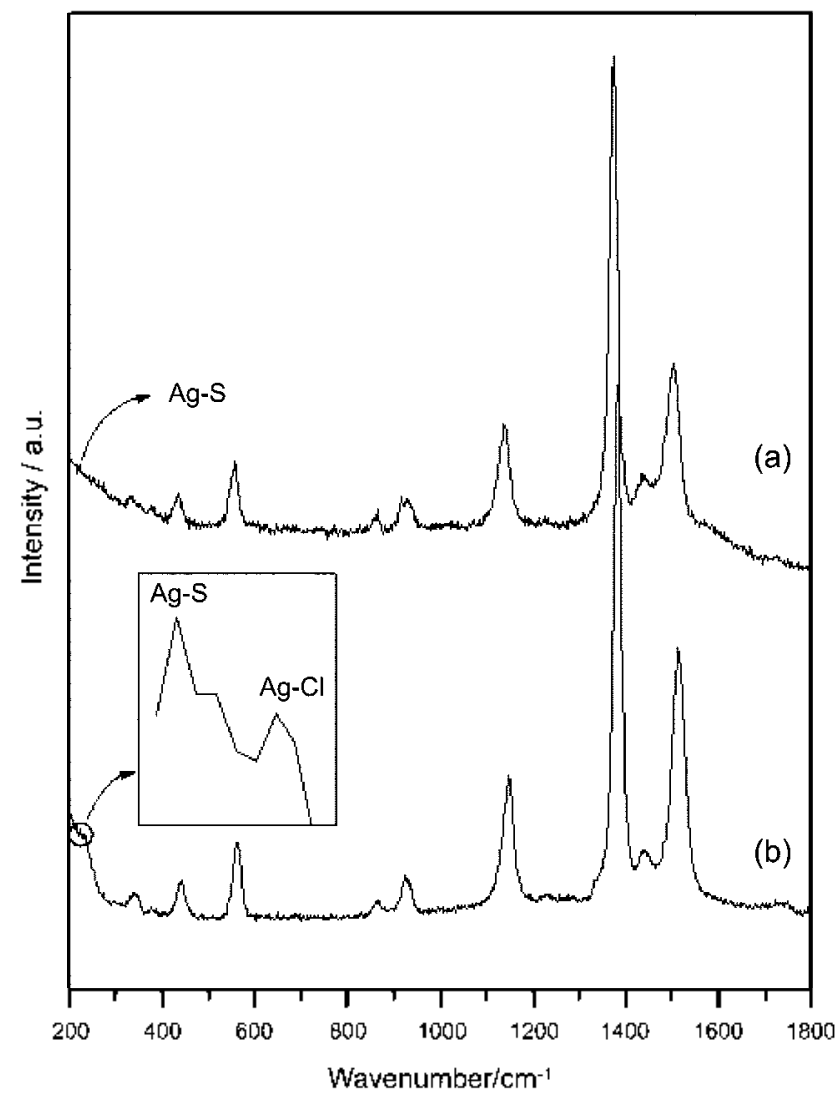

Figure 5. SLR spectra of $1.0 \times 10^{+} \mathrm{M}$ thiram in silver sol containing (a) $0.5 \mathrm{~N} \mathrm{KBrt} \mathrm{(b)} 0.5 \mathrm{~N} \mathrm{KCl}$.

$(\mathrm{C}=\mathrm{S})$ modes were strongly affected in the SER spectrum.

Several researchers have studied the metal-sulfur stretching bands between 200 and $250 \mathrm{~cm}^{-1} .1-2.37$ In this paper. new bands at $220-240 \mathrm{~cm}^{-1}$ in the SER spectrum of thiram were found. It is supposed that this peak at around $226 \mathrm{~cm}^{-1}$ can be attributed to the silver-sulfur stretching vibration. Figure 5 shows SER spectra of thiram containing $0.5 \mathrm{M} \mathrm{KCl}$ and $0.5 \mathrm{M} \mathrm{KBr}$ as electrolyte. According to previous investigators, the silver-chloride stretching vibration is shown around $240 \mathrm{~cm}^{-1}$. Additionally the silver-sulfur stretching vibration at around $220 \mathrm{~cm}^{-1}$ is indistinct. ${ }^{-7}$ The $226 \mathrm{~cm}^{-1}$ band was observed on silver in solution containing $0.5 \mathrm{M}$ $\mathrm{KBr}$ and $1.0 \times 10^{-4} \mathrm{M}$ thiram (Fig. 5a). Thus, it can be assumed that the line at $226 \mathrm{~cm}^{-1}$ is due to the silver-sulfur stretching mode because of the presence of an identical peak in both clloride and bromide anion. In addition, it can be assumed that the line at $236 \mathrm{~cm}^{-1}$ (Fig. 5b) is due to the silver-chloride stretching mode.

Therefore. experimental obsenations suggest that only a single thiram molecule will bond to the silver surface via the two $S$ atoms, and that halide ions in the interface near the silver surface affect the silver adsorbate vibration which will form a stable complex formation.

The Influence of Anions. SER spectra of thiram adsorbed on a silver surface have been observed from a series of aqueous solutions containing $\mathrm{F}^{-}, \mathrm{Cl}^{-}, \mathrm{Br}^{-}$and $\mathrm{I}^{-}$as electroly te. ${ }^{-\cdots "}$ It is known that the cation has essentially no

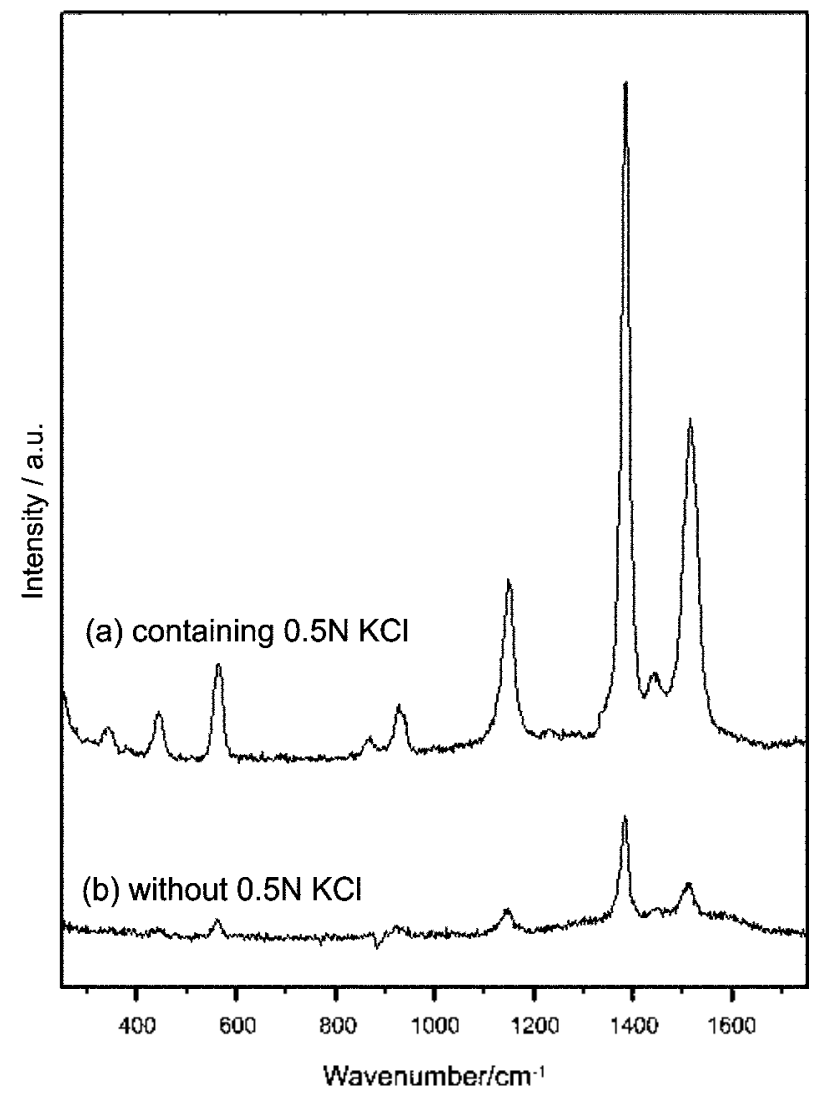

Figure 6. SF.R spectra of $1.0 \times 10^{-1} \mathrm{M}$ thiram in silver sol (a) conlaining $0.5 \mathrm{~N} \mathrm{KCl}$ (b) withoul $0.5 \mathrm{~N} \mathrm{KCl}$.

effect on the spectrum. The important role of anion adsorption has been discussed. Generally. it increases the intensity of the Raman signal of the adsorbed molecule. Studies by Pettinger, Roy, Furtak. Fleischman. and Watanabe have shown that an electrochemically roughened silver electrode presents a surface containing $\mathrm{Ag}$ ' ions that are stabilized by coadsorbed $\mathrm{Cl}^{-}$ion, a constituent of the electrolyte. ${ }^{2 *}$ The roles of stabilizing $\mathrm{Cl}^{-}$ions or other coadsorbed species on a positively charged Ag ion have been predicted and then experimentally verified.

First of all. we are going to investigate the influence of surface $\mathrm{Cl}^{-}$ions on the SER spectra of thiram. Figure 6 shows the SER spectra of thiram in the presence and the absence of $\mathrm{Cl}^{-}$. The SER spectra of thiram containing a $\mathrm{Cl}^{-}$ ion are stronger and sharper than in the absence of $\mathrm{Cl}^{-}$. It is important to point out that the presence of $\mathrm{Cl}^{-}$ions increase reproducibility of the SER spectra of thiram. This enhancement may originate from the induction of positive charges by the coadsorbed chloride ion that leads to an increase in the interaction between thiram and the silver surface.

To better understand the underlaving mechanism. we investigated UV-visible spectra of sol containing $\mathrm{Cl}^{-}$. After addition of $\mathrm{Cl}^{-}$ion. the aggregation peak at $c a+50$ rum was reduced and broader than that of sol without $\mathrm{Cl}^{-}$. Cortes showed that this causes a breakup of the loose aggregates of elementary colloidal particles. ${ }^{29}$ Thus. $\mathrm{Cl}^{-}$addition leads to a small degree of dispersion from the aggregated surface. and 


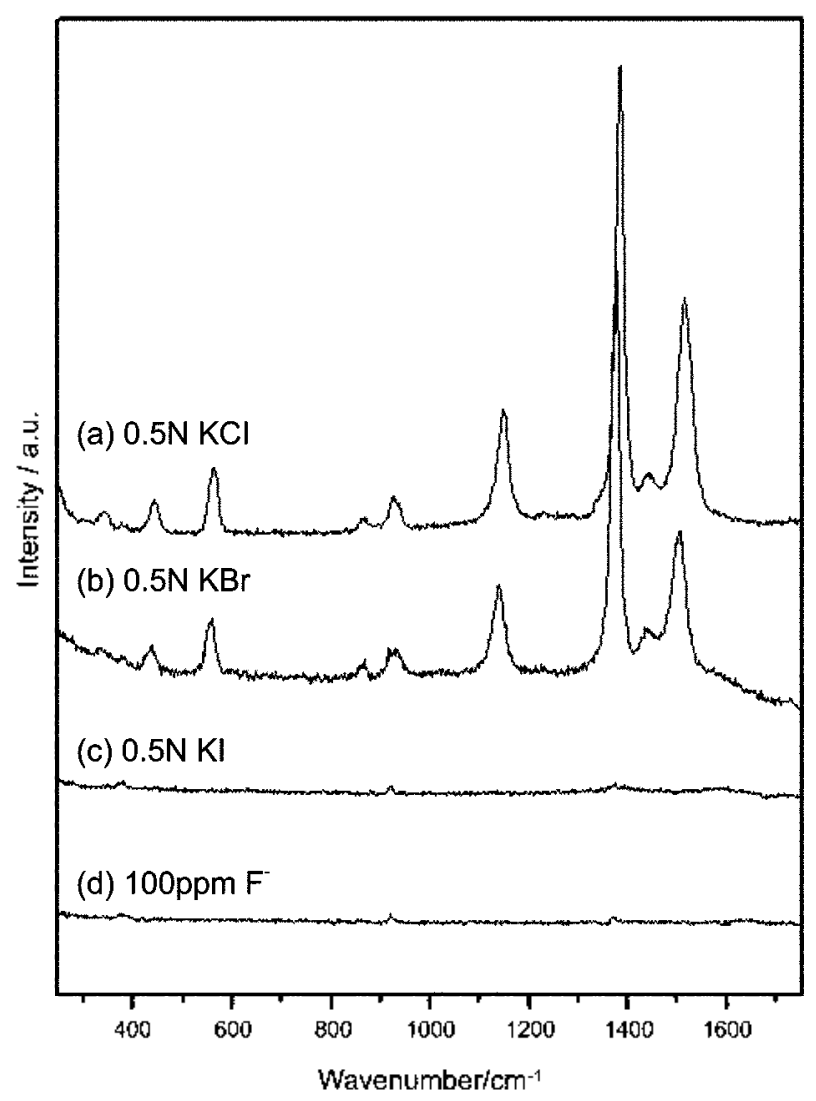

Figure 7. SFR spectra of $1.0 \times 10^{-1} \mathrm{M}$ thitam in silver sol containing (a) $0.5 \mathrm{~N} \mathrm{KCl}$ (b) $0.5 \mathrm{~N} \mathrm{KBr}$ (c) $0.5 \mathrm{~N} \mathrm{KI}$ (d) 100 ppm $\mathrm{F}^{-}$.

the formation of $\mathrm{Ag}^{\prime}-\mathrm{Cl}^{-}$on substrate offers proper active sites.

Additionally; these observations provide more evidence for the importance of surface complexes in the SER process on sol. When a complex forms between the active site and a probe molecule this involves a bond that is stimulated by the number of adsorbed $\mathrm{Cl}^{-}$ions around the $\mathrm{Ag}$ sol. Thus. this bond leads to modifications in the relative Raman polarizabilities. Desorbing of $\mathrm{Cl}^{-}$ions on the Ag surface bring about unstable surface complexes, which are deactivated by being left with insufficient $\mathrm{Cl}^{-}$ions to hold the $\mathrm{Ag}$ on the surface. The inactive sites do not contribute to SERS. leading to a decrease in the scattering intensity: Therefore, only pertinent $\mathrm{Cl}^{-}$ion coverage on Ag surfaces is important. Finally. a $\mathrm{Cl}^{-}$ion is necessary to enhance Raman scattering and prevent photoreaction of the silver surface.

To understand the coverage degree of anions on silver surface, the SER spectra of aqueous solutions containing $\mathrm{F}^{-}$. $\mathrm{Cl}^{-} . \mathrm{Br}^{-}$, and $\mathrm{I}^{-}$ions are exhibited in Figure 7. These results are in good agreement with some of the predictions of previous researchers. The SER spectrum from the $\mathrm{Br}^{-}$ solution in Figure $7 \mathrm{~b}$ is quite similar to that from the $\mathrm{Cl}^{-}$ solution in Figure 7a. In this case, the overall spectral feature hardly changed except for some noise from the $\mathrm{Br}^{-}$solution in Figure $7 \mathrm{~b}$. Therefore. it is supposed that bromide ions are more strongly adsorbed than chloride ions on silver. UVvisible absorption experiments suggest that $\mathrm{Br}^{-}$and $\mathrm{Cl}^{-}$ions are similar in their influence on the substrate.$^{3 i)}$ Figures $7 \mathrm{c}$ and $7 \mathrm{~d}$ show similar SER spectra for $\mathrm{F}^{-}$and $\mathrm{I}^{-}$ions as electrolytes. For silver halide systems. the surface concentrations of specifically adsorbed anions were reported by Hupp et al $^{2-3 \times 1} \mathrm{l}^{-}$ion is tenaciously adsorbed on a silver surface and an $\mathrm{F}^{-}$ion is adsorbed very weakly. so that the SER spectrum is very poor. An increase in spectral intensity is associated with fitting in the surface coverage of the specifically adsorbed anions. Thus. a $\mathrm{Cl}^{-}$ion is very pertinent among anions. The presence of halide ions was a prerequisite for the observation of SERS using hydrosol.

The Effect of Solution $\mathrm{pH}$. The following experiments were performed in order to investigate the $\mathrm{pH}$ effect of thiram on the SER spectrum. Solutions were prepared with various $\mathrm{pH}$ ranging from acidic to alkali conditions. Many researchers have investigated the effect of solution $\mathrm{pH}$ on the SERS behavior of adsorbates in order to determine the adsorption mechanism or the orientation of adsorbates. ${ }^{31,32}$

The SER spectra in Figure 8 are for silver sol in acidic. neutral. and alkali conditions. In acidic and neutral conditions. similar SER spectra are shown. This shows that adsorption in acidic and neutral conditions is about the same. In spite of a various range of acidic conditions. peak patterns did not differ. as shown in Figure 9.

Figure 10 shows SERS of thiram in alkali condition. Most of all, all peaks decreased on a large scale in intensity: In

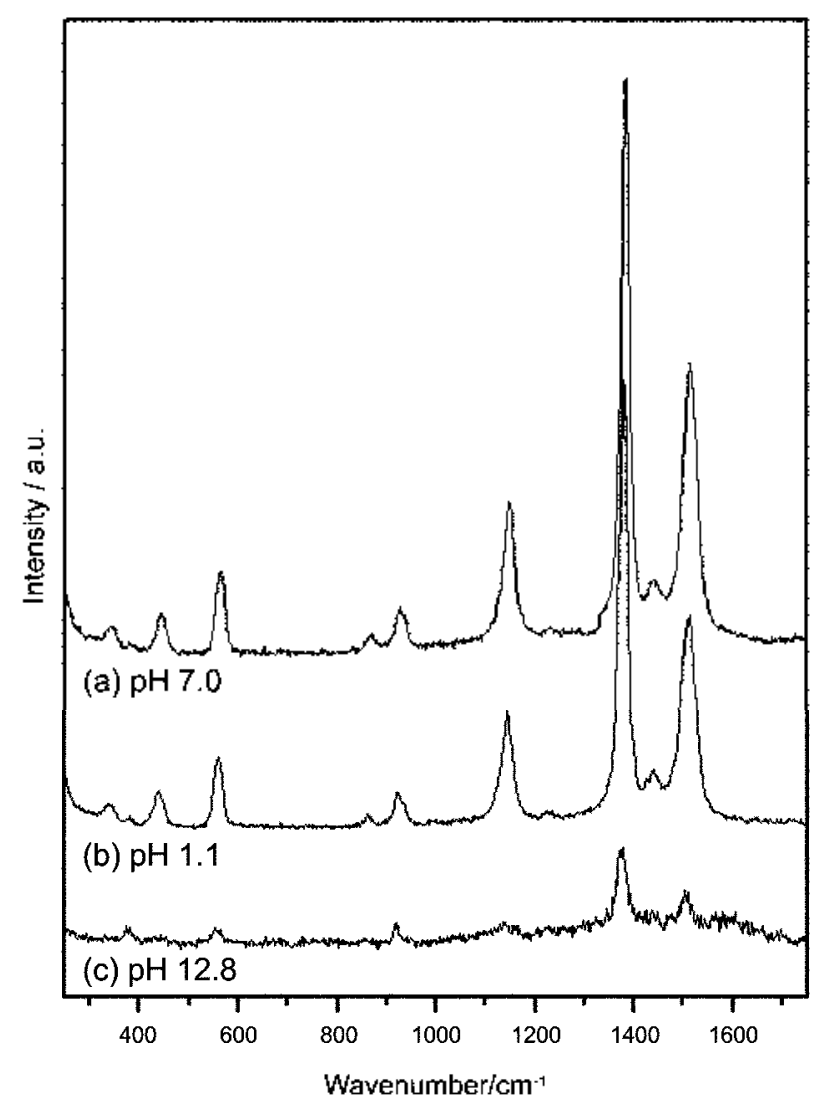

Figure 8. SER spectra of $1.0 \times 10^{-1} \mathrm{M}$ thiram in silver sol containing $0.5 \mathrm{~N} \mathrm{KCl}$ at (a) neutral $(\mathrm{pH}=7.0)(\mathrm{b})$ acidic $(\mathrm{pH}=1.1)(\mathrm{c})$ alkali ( $p \mathrm{H}=12.8$ ). 


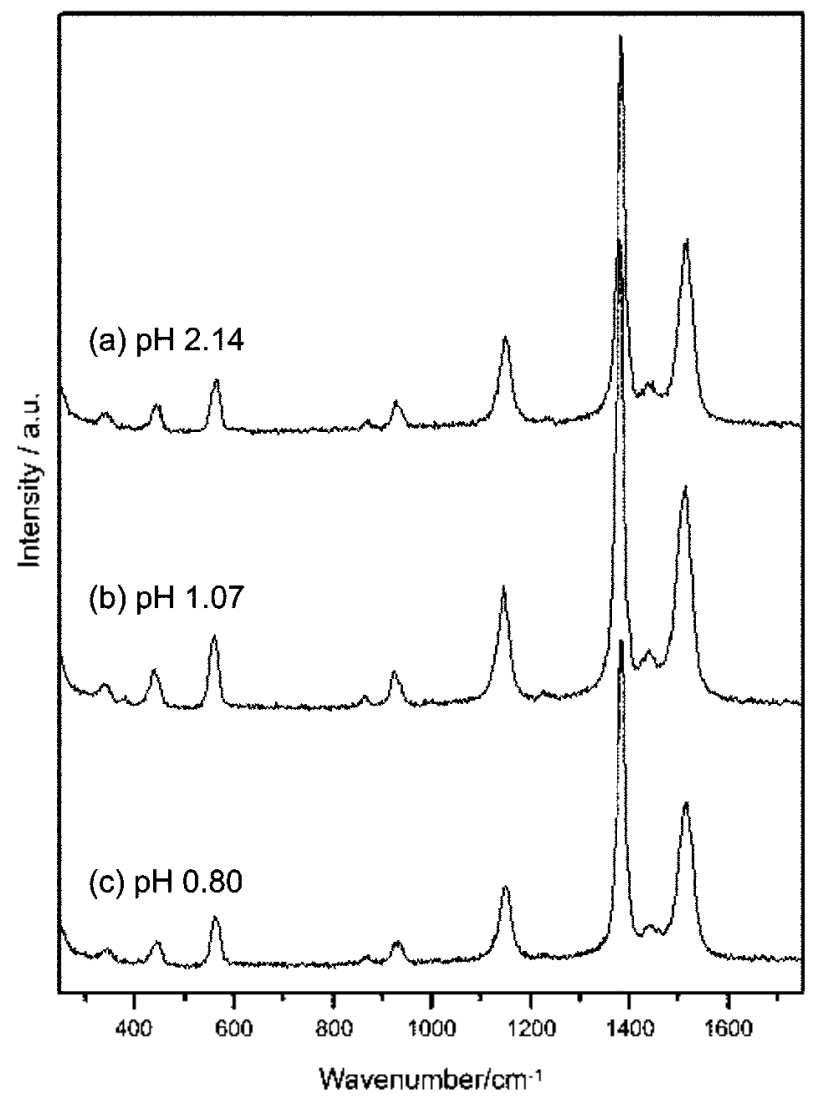

Figure 9. SLR spectra of $1.0 \times 10^{-1} \mathrm{M}$ thiram in silver sol containing $0.5 \mathrm{~N} \mathrm{KCl} \mathrm{al} \mathrm{(a)} \mathrm{pll}=2.14$ (b) $\mathrm{pH}=1.07$ (c) $\mathrm{pll}=0.80$.

particular. the peaks around $370-390 \mathrm{~cm}^{-1}$ in Figure 10 increased as the $\mathrm{pH}$ increased. In light of the above results, it can be concluded that the bonding of two $\mathrm{S}$ atoms on $\mathrm{Ag}$ sol is weak: thus, the intensity of $\left(\mathrm{CH}_{3}\right)$ and $(\mathrm{CN})$ modes which are perpendicular to the substrate decreased. Thus. for the higher $\mathrm{pH}(11$ to 14$)$. orientation of thiram on the $\mathrm{Ag}$ sol is more tilted on the Ag surface.

As the $\mathrm{pH}$ is increased from 11 to $1+$. the peaks at 1300 $1500 \mathrm{~cm}^{-1}$ are broader than in acidic conditions. The competitive adsorption of the $\mathrm{OH}^{-}$ion and $\mathrm{Cl}^{-}$ion on silver surface has been reported. ${ }^{32}$ As the $\mathrm{pH}$ is increased, surface sites are occupied by the $\mathrm{OH}^{-}$ion rather than the $\mathrm{Cl}^{-}$ion. A strong influence of $\mathrm{OH}^{-}$ion on this competitive adsorption is seen in Figure 10. A broad band around $1300-1500 \mathrm{~cm}^{-1}$ is very likely caused by reduction of the extent of the surface coverage of $\mathrm{Cl}^{-}$ions.

Finally: this experimental study shows that adsorption patterns in neutral and acidic conditions are similar. but as the $\mathrm{pH}$ is increased thiram is bonded to tilted stances on the Ag surface via the two $S$ atoms. It can be suggested that the change of adsorption orientation in alkalic conditions is explained by inactive sites that are left with insufficient $\mathrm{Cl}^{-}$ ions due to the competitive adsorption of $\mathrm{OH}^{-}$ions.

\section{Conclusion}

The Raman process is associated with a low photon

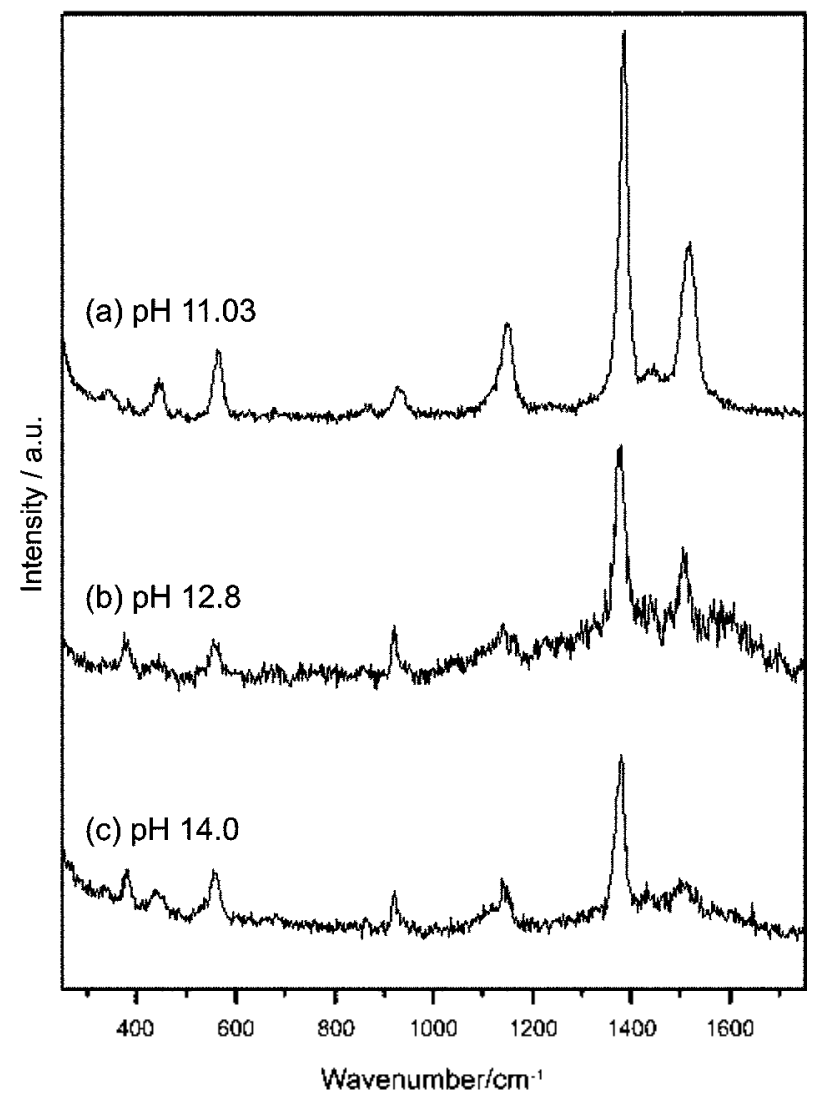

Figure 10. SFR spectra of $1.0 \times 10^{-1} \mathrm{M}$ thiram in silver sol conlaining $0.5 \mathrm{~N} \mathrm{KCl} \mathrm{al} \mathrm{(a)} \mathrm{pH}=11.03$ (b) $\mathrm{pH}=12.8$ (c) $\mathrm{pH}=14.0$.

scattering efficiency. Although multichannel photon detectors have enhanced Raman sensitivities. the technique is still limited in surface studies and at low concentrations. In the present work. we studied thiram on silver surface by SERS. Investigations of disulfides with SERS revealed that the molecules undergo surface reaction on silver. namely easy cleavage of the S-S bond. We believe that the two $\mathrm{S}$ atoms of resonance formed from the thiram may be chemisorbed strongly on $\mathrm{Ag}$ sol. This resonance form is adhered perpendicularly to the $\mathrm{Ag}$ surface via the two $\mathrm{S}$ atoms, since the $\left(\mathrm{CH}_{3}\right)$ and $(\mathrm{CN})$ mode perpendicular to the surface showed strong enhancement. The important roles of halide anion adsorption have been discussed. Among the halide anions. addition of $\mathrm{F}^{-}$and $\mathrm{I}^{-}$ions resulted in very poor spectra of SERS. In the case of $\mathrm{Br}^{-}$and $\mathrm{Cl}^{-}$ions. good results were obtained, excepting minute noise from the $\mathrm{Br}^{-}$ solution. Thus. $\mathrm{Cl}^{-}$ion has a proper coverage and stability on Ag surface. The $\mathrm{pH}$ effects of thiram on $\mathrm{Ag}$ sol in acidic, neutral and alkali conditions were examined. For acidic and neutral conditions, orientations of thiram on $\mathrm{Ag}$ sol are perpendicular to the silver surface. showing good SERS spectra. However, for the alkali conditions. orientations of thiram on Ag sol are slightly tilted on the silver surface. As the $\mathrm{pH}$ increased from 11 to $\mathrm{It}$. the peaks at $1300-1500 \mathrm{~cm}^{-1}$ were broader than in acidic conditions. This shows the competitive adsorption of the $\mathrm{OH}^{-}$ion and $\mathrm{Cl}^{-}$ion on the silver surface. 
Acknowledgment. This research was suppoited by Kỵungook National University Research Fund. 2001.

\section{References}

1. Shrface Fnhanced Raman Scattering: Chang. R. K.. Furtak. T. E. Eds.: Plenum: Nen York. 1982.

2. Creighton. J. A. Komom Spectroscopy of Adsombaths at thotal Swfoce in librational Spectroscopy of telsorbates: springer series in chemical plusies: Wills. R. F.. Fd.: Springer: Berlin. IJeidelberg. New York, 1980: vol. 15, p 145.

3. Joo, S. W. IJan. S. W.: Kim, K. J. Colloid herfface Sici. 2001. 240.391 .

4. Jung. Y. M.: Lim. I. W.: Kim. E. R.: Lee. H.: Lee. M. S. Bull. Nonem Chem. Soc, 2001. 22. 318 .

5. 7cman, E. J: Schat7. G. C. J. Phws (Them. 1987.91,634.

6. Matcjka. P.: Vlckova. B.: Voll]ichol. J.: Pancoska, P.: Banmutuk. V. J. Phys ( $h e m .1992,96,1.361$.

7. Moskoxils. M. Rov Hod. Phrs. 1985. 57.783.

8. Moskovils. M.: Suh. J. S. J. Phws. Chem. 1984. 88.5526.

9. Sult. J. S. J. Aon'on Chem. Soc. 1992. 36. 327.

10. Yim. Y. J1.: Kim, K.: Kim. M. S. J. Phs ( $/ h^{2 m}$ 1990, 94. 2552.

11. Cardona. M.: Guntherodt, G. Jight Scattering in Solds: Spritiger: Berlin. 1984: Vol. IV.

12. Mat1hens. G. A.: Hislop. E. C. Apptication lechologe for Crop Proterion: 1993

13. Danuich. J.: Zirulnik. F.: Gimenè. M. S. Eininom. Res. 2001. 85. 226 .

14. Anderson, M. R.: Frans, D. I1. J Im. (Them. Soc 1988. 110.6612.
15. Albrecht. M. G.: Creighton. A. A. J. Am. Chkm. Soc, 1977. 99. 5215 .

16. Lee. S. B.: Kim. K.: Kim. M. S. J. Hhs Chm. 1992. 96.9940.

17. Watanabe. T.: Macda, I1.J. Phys. (hem 1989, 93, 3258.

18. Macomber, S. I1.; Furtak, T. F. (Wen Phus Lett. 1982. $90(1) .59$.

19. Joo, T. I.: Yim, Y. H.: Kim. K.: Kim, M. S. J. Phys (hem 1989. 93. 1422 .

20. Kwon. C. K.: Kim. K.: Kim. M. S.: Lee. S. B. Bull. Konn Chem. Soc: 1989. $10(3) .254$

21. Nichols. I I.: I Lexter, R. M. J. ( Wem. Phys. 1981, 7f. 2059.

22. Weaver, M. J.: I Iupp, J. T. J. Flectrowhal Chem 1984, 160. 321.

23. Wet7el. I1.: Gerischer, H.: Pettinger, B. ('hem Phys Lett. 1981. 78.392 .

24. Low. B. H. Ch'm. Ihws Luff 1982. 89(4). 346.

25. P'ettinger. B.: P'hillpott. M. R.: Gordon. J. G. J. Hhy. Chem. 1981. 85.2746

26. Takahashi, M.: Furukwa, II.: Fujita. M.: Ito. M. J. Phus. ('hem. $1987,91.5940$

27. Garrel. R. L.: Shan. K. D.: Krimm. S. J. Chem. Thens 1981. 75(8). 4155.

28. Muniz-Miranda. M.: Sbrana. G. J. Romem Spectrosc: 1996. 27. 105.

29. Sanches-Cottes. S.: Garcia-Ramos, J. V. J. Raman Speetrosc. $1992,23.61$

30. Larkin. D.: Guyer. K. L.: Hupp. .T. I': Weaver. M. I. J. Electrosmal. Chem. 1982. 138. 401 .

31. Kim. M.: Koichi. I. J. Phys. Chem. 1987.91. 126.

32. Salaita. G. N.: I.u. F.. I anguren-Davidson. I.: Hubbard, $A$. T. J. Electronal. (hem. 1987, 229.1. 